\title{
Serbest Zaman Engelleri ile İlgilenim Arasındaki İlişki: Fitness Merkezi Katılımcıları Üzerine Bir Araştırma
}

\author{
Emrah SERDAR ${ }^{1}$ (i) \\ ${ }^{1}$ İstanbul Üniversitesi-Cerrahpaşa, Spor Bilimleri Fakültesi, İstanbul.
}

Orijinal Makale

Gönderi Tarihi: 01.03.2021
Kabul Tarihi: 24.04.2021
DOI:10.25307/jssr.889333

Online Yayın Tarihi: 30.06.2021

Öz

Araştırmanın amacı, fitness merkezini kullanan bireylerin serbest zaman faaliyetlerine ilişkin engelleri ile ilgilenimleri arasındaki ilişkinin belirlenmesidir. Araştırmanın örneklemini, İstanbul ilinde bulunan özel fitness merkezine üye olan ve amaçlı örnekleme yöntemi ile belirlenen toplamda 216 kişi oluşturmuştur. Araştırmada veri toplama aracı olarak, Alexandris ve Carroll (1997) tarafından geliştirilen ve Gürbüz ve vd., (2020) tarafından Türkçe 'ye uyarlanan "Boş Zaman Engelleri Ölçeği (BZEÖ)" ile Kyle ve vd., (2007) tarafından geliştirilen ve Gürbüz ve vd., (2018) tarafindan Türkçe'ye uyarlanan "Serbest Zaman İlgilenim Ölçeği (SZïÖ)" kullanılmışır. Analiz olarak ise, betimsel istatistikler, MANOVA ve Pearson korelasyon analizlerinden faydalanılmıştır. MANOVA analizi sonuçları; "Fitness Merkezi Kullanım Siklıkları" göre boş zaman engelleri ölçeğinin "Birey Psikolojisi" ve "Tesis" alt boyutunda anlamlı farklılık olduğu belirlenmiştir. SZIÖ’ne ilişkin MANOVA analizi sonuçlarına göre; "Cinsiyete" göre SZİÖ’nin "Önem Verme" alt boyutunda anlamlı farklılık olduğu, bireylerin "Fitness Merkezi Kullanım S1klıklarına" göre ise, SZİÖ’nin tüm alt boyutları üzerindeki ana etkisinin anlamlı olduğu belirlenmiştir. Son olarak ise, Yaş ile BZEÖ'nin alt boyutları arasında sadece "Tesis" ile düşük ve pozitif bir ilişki; Yaş ile SZIÖ’nin alt boyutları arasında ise "Çekicilik", "Önem Verme", "Özdeşleşme” ve "Kendini ifade" arasında ise düşük ve pozitif yönde bir ilişki olduğu ortaya çıkmıştır. "BZEÖ” ile "SZIÖ”" arasındaki ilişki incelendiğinde ise; "BZEÖ" ile "SZİ̈̈" arasında ilişki olmadığı saptanmıştır. Sonuç olarak, bireylerin serbest zaman engelleri ile ilgilenimlerinin farklı değişkenlere göre farklılık gösterdiği, BZEÖ ile SZİÖ arasında ilişki olmadığı sonucuna varılmıştır.

Anahtar Kelimeler: Fitness merkezi, Serbest zaman engelleri, Serbest Zaman ilgilenimi.

\section{The Relationship Between Leisure Constraints and Leisure Involvement: A Research About Fitness Center Members}

\begin{abstract}
The study aimed to determine the relationship between the leisure constraints and involvements of private fitness centre members. The sample of the study consisted of 216 people who were members of private fitness centre in Istanbul and selected by the purposeful sampling method. The Leisure Constraints Scale (LCS) developed by Alexandris and Carroll (1997) and adapted into Turkish by Gürbüz et al. (2020), and the "Leisure Involvement Scale (LIS)" developed by Kyle et al., (2007) and adapted into Turkish by Gürbüz et al. (2018) were used as data collection tools. Descriptive statistics, MANOVA and Pearson correlation analysis used to analyse data. According to MANOVA analysis, it was determined that there was a significant difference in the "Facility" and "Individual Psychology" subscales regarding "Frequency of Fitness Centre Usage". The results of MANOVA analysis on LIS showed that there was a significant difference in "centrality" subscales according to gender, and there was a significant difference in all subscales according to the Frequency of Fitness Centre Usage. Moreover, there was a low and positive relationship between Age and "Facility" subscales of LCS. A low and positive relationship was found between age and LIS subscales. When the relationship between "LCS" and "LIS" was examined, it was determined that there was no relationship between scales. As a result, it was concluded that individuals' leisure involvement and constraints differed according to different variables, and there was no relationship between LIS and LCS.
\end{abstract}

Keywords: Fitness centres, Leisure constraints, Leisure involvement. 


\section{GíRiş}

Günümüzde, bireylerin yaşam koşullarında sağlanan kolaylıklar ve çalışma saatlerinin azalması sonucunda serbest zamanların arttığı bilinmektedir (Demirel, 2019; Serdar ve Ay, 2016; Tolukan, 2010). Serbest zamanlarda meydana gelen bu artış, kişilerin yaşamlarında pek çok faydayı da beraberinde getirdiği gibi (Eccles, 2005; Gürbüz vd., 2018; Kim vd., 2018), serbest zaman katılımı ve serbest zaman katılım sorunsalına yönelik ilgiyi de arttırdığ belirtilmiştir (Lapa ve Köse, 2018). Serbest zaman katılımı, bireylerin zorunlu çalışma saatleri dışında kalan zaman diliminde serbest zaman aktivitelerine yönelik katılım sıklıklarını ve sürelerini işlevsel hale getiren davranışsal bir kavram olarak tanımlanmaktadır (Kuykendall vd., 2015; Matsumoto vd., 2018). Serbest zaman katılımı sonucunda bireyler çeşitli yönlerden faydalar elde etmektedirler. Alanyazında serbest zamanda elde edilen faydalar genellikle fizyolojik, psikolojik ve sosyal faydalar olmak üzere üç başlık altında sınıflandırılmaktadır (Hung, 2012; Yan, 2013). Bu faydalara örnek olarak; kardiyovasküler sağlık, hastalıkların yönetimi, zihinsel ve fiziksel rehabilitasyon gibi fizyolojik faydalar (Bright, 2000; Kuo, 2013); özgürlük hissi, kendine değer verme duygusu, benlik saygısının gelişimi, depresyon, endişe ve öfke azalımı gibi psikolojik faydalar (Chen, 2001; Ho, 2008; Iso-Ahola, 1997; Mannell ve Stynes, 1991; Wankel ve Berger, 1991); bireyler yeni arkadaşlıklar ve ilişkiler kurma, insanların duygularını anlamayı ve başkalarının güvenini kazanmaya yönelik sosyal faydalar elde etmektedirler (Chen, 2001; Eskiler vd, 2019). Serbest zaman aktivitelerine kat1lımın bireyler üzerinde olumlu etkileri olmasına rağmen insanlar çeşitli sebeplerden ötürü kendileri için faydalı olan bu aktivitelere katılamadıkları veya farklı engellerle karşılaştıkları belirtilmiştir (Demirel ve Harmandar, 2009). Engeller literatüründe, serbest zaman engelleri ile serbest zaman katılımları arasında negatif yönde bir ilişki olduğu yani insanların algıladıkları kısıtlamaların aktiviteye katılmama ya da katılımı azaltmaya yol açtığı kabul edilmektedir (Alexandris ve Carroll, 1997). Serbest zaman engelleri, kişilerin serbest zaman tercihlerini etkileyen, katılımlarını kısıtlayan ya da keyif ve memnuniyet seviyelerini azaltacak etmenler olarak açıklanmaktadır (Jun ve Kyle, 2011; Sarol, 2017). Serbest zaman etkinliklerine katılımı engelleyen etmenler; bireysel, bireylerarası ve yapısal olmak üzere üç gruba ayrılmaktadır (Alexandris vd., 2017; Crawford ve Godbey, 1987). Bireysel engeller; bireylerin algiladiklar1 yetenekleri, zindelik durumları, benlik saygısı, aktiviteye yönelik ilgi ve katılımda güven gibi psikolojik durumlar ve algilar ile ilgili etmenlerdir. Bireylerarası engeller; serbest zaman katılımda arkadaş ve partner bulmadaki zorluklar ile ilgili faktörlerdir. Yapısal engeller ise; finansal sorunlar, kaynak eksikliği, erişebilirlik ve hizmet kalitesi sorunları gibi dış faktörlerdir (Alexandris vd., 2008).

Serbest zaman ilgilenimi konusu, bilim insanları tarafindan bireylerin serbest zaman faaliyetlerine yönelik davranışlarını ve tutumlarını anlamak amacıyla ele alınmış (Alexandris vd., 2013; Cheng ve Tsaur, 2012; Kyle ve Chick, 2004; Sato vd., 2017) ve serbest zaman aktivitesine veya ürüne karşı gözlenemeyen bir motivasyon, uyarılma veya ilgi durumu olarak tanımlanmaktadır (Havitz ve Dimanche, 1997). Alanyazında serbest zaman ilgilenimi ile ilgili yaygın olarak kullanılan model McIntype ve Pigram (1992)'ın çalışması temel alınarak, Kyle vd., (2003) ile Kyle vd., (2004) tarafından geliştirilen üç boyutlu modeldir (Alexandris vd., 2013). Model'de yer alan çekicilik, kendini ifade ve önem verme alt boyutlarının yanında sosyal ilişki ve özdeşleşme alt boyutları da modele dahil edilmiştir (Aydın, 2016; Kyle vd., 2007). Çekicilik; aktivitenin bireyler için önemini ve ondan aldığı zevki ve memnuniyeti ifade etmektedir (Chang ve Gibson, 2011). Önem verme; aktivitelerin bireylerin günlük yaşamlarının 
ne kadar merkezinde olduğu ile ilgilidir (Kyle ve Chick, 2004). Sosyal ilişki; bireyleri serbest zaman aktivitelerine bağlayan sosyal bağlar olarak ifade etmektedir (Aydın, 2016). Özdeşleşme; bireylerin katıldıkları serbest zaman aktiviteleri aracılığıyla kendilerini onaylama durumu olarak açıklanmaktadır (Aydın, 2016). Kendini ifade ise; bireylerin serbest zaman katılımları ile diğer insanlara aktarmak istedikleri benlik izlenimlerini ifade eden sembolik bir boyutu temsil etmektedir (Chang, 2017). Engeller kavramı, bireylerin serbest zaman kat1lımları açısından karar verme süreçlerinin yönlerini belirlemek için; (Alexandris vd., 2008; Alexandris vd., 2002; Mannell ve Iwasaki, 2005; Mannell ve Loucks-Atkinson, 2005) serbest zaman ilgilenimi ise, bireylerin serbest zaman davranışlarında karar verme süreçlerini anlamak için kullanıldığı belirtilmiştir (Alexandris vd., 2008; Iwasaki ve Havitz, 2004).

Bireylerin serbest zaman aktivitelerine katılımlarını engelleyen faktörler ile onların aktivitelere yönelik ilgilenim düzeylerinin belirlenmesi alanyazına katkı sağlayacağı düşünülmektedir. $\mathrm{Bu}$ bağlamda araştırmanın amacı, fitness merkezini kullanan bireylerin serbest zaman engelleri ile ilgilenimleri arasındaki ilişkinin belirlenmesidir.

\section{YÖNTEM}

\section{Araştırma Modeli}

Fitness merkezine üye olan bireylerin serbest zaman engelleri ile ilgilenimleri arasındaki ilişkinin belirlenebilmesi amacıyla ilişkisel tarama modeli kullanılmıştır. Kavramsal olarak ilişkisel tarama modeli günümüzde ya da geçmişteki durumları, değişimine, şiddetine ve yönüne göre belirlemeye ilişkin çalışmalar şeklinde tanımlanabilmektedir (Karasar, 2014).

\section{Araştırma Grubu}

İstanbul ilinde bulunan özel fitness merkezinde üye olan, amaçlı örnekleme yöntemi ile seçilen 128 kadın $\left(\right.$ Ort $\left._{\text {yaş }}=25.66 \pm 7.16\right)$ ve 88 Erkek $\left(\right.$ Ortyaş $\left._{\text {y }}=25.93 \pm 7.51\right)$ olmak üzere toplamda 216 kişi araştırma grubunu oluşturmuştur. Araştırmaya katılanların \%45,4'ünün refah durumu "Normal”, \%39,8'i haftalık fitness merkezine "1-3 gün” arasında gitmekte iken, \%38,0'nın ise haftalık "6-10 Saat” arasında serbest zamana sahip oldukları belirlenmiştir.

\section{Araştırma Yayın Etiği}

$\mathrm{Bu}$ araştırma İstanbul Üniversitesi-Cerrahpaşa Sosyal ve Beşeri Bilimler Araştırmaları Etik Kurul başkanlığının 02.06.2020 tarihli 71884 sayılı kararı sonucunda çalışmanın etik açıdan uygun olduğuna oybirliği ile karar verilmiştir.

\section{Veri Toplama Araçları}

Kişisel Bilgi Formu: Çalışmaya gönüllü olarak dahil olan katılımcıların demografik durumları ile ilgili bilgi almak için araştırmacı tarafından hazırlanan "Kişisel Bilgi Formu"; eğitim durumu, cinsiyet, yaş, haftalık serbest zaman süreleri ve medeni durum gibi sorulardan oluşmaktadir.

Boş Zaman Engelleri Ölçeği-Kısa Formu: Katılımcıların serbest zaman aktivitelerine katılımlarını engelleyen faktörleri tespit etmek için "Boş Zaman Engelleri Ölçeği (BZEÖ)" 
kullanılmıştır. Ölçek, Alexandris ve Carroll (1997) tarafından geliştirilmiş olup, ilk olarak Gürbüz ve Karaküçük tarafindan (2007) "Boş Zaman Engelleri Ölçeği-28" olarak Türkçe'ye uyarlanmış olup, bu araştırmada ise, Gürbüz vd., (2020) tarafindan "Boş Zaman Engelleri Ölçeği-Kısa Formu" kullanılmıştır. Toplam 18 madde ve "Birey Psikolojisi”, "Bilgi Eksikliği”, "Tesis", "Arkadaş Eksikliği”, "Zaman" ve "İlgi Eksikliği” olmak üzere 6 alt boyuttan oluşmaktadır. Maddeler (1) Kesinlikle Önemsiz, (4) Çok Önemli şeklinde cevaplanmaktadır. Gürbüz vd., (2020) tarafından ölçeğin iç tutarlılık kat sayıları sırasıyla; 0.77, 0.86, 0.80, 0,81, 0.65 ve 0.76 şekilde belirlenmiştir.

Serbest Zaman İlgilenim Ölçeği: Katılımcıların serbest zaman aktivitelerine yönelik ilgilenim düzeylerini tespit etmek için ise, "Serbest Zaman İlginim Ölçeği (SZIÖ)" kullanılmıştır. SZï̈; Kyle vd., (2007) tarafından geliştirilmiş olup ve Gürbüz vd., (2018) tarafından Türkçe "ye uyarlaması yapılmıştır. Toplam 15 madde ve "Çekicilik", "Önem Verme", "Sosyal İlişki", "Özdeşleşme" ve "Kendini İfade" olmak üzere 5 alt boyuttan oluşmaktadır. Ölçek likert tipi derecelendirme ile 1-5 arasında puanlanmaktadır. Gürbüz vd., (2018) tarafından ölçeğin iç tutarlılık kat sayıları sırasıyla; $0.80,0.66,0.70,0,58$ ve 0.67 şekilde tespit edilmiştir.

\section{Verilerin Analizi}

Araştırma kapsamında toplanan veriler, SPSS 20.0 paket programında değerlendirilmiştir. Verilerin normal dağılım gösterip göstermediğini belirlemek amacıyla çarpıklık ve basıklık değerleri incelenmiş olup, verilerin normal dağılım gösterdiği anlaşılmıştır. Verilerin değerlendirilmesinde, betimsel istatistikler, MANOVA ve Pearson Korelasyon analizlerinden faydalanılmıştır. Güvenirlik tespiti için Cronbcah Alpha katsayıları incelenmiştir.

\section{BULGULAR}

Tablo 1. Ölçek puanlarının dağılımı

\begin{tabular}{|c|c|c|c|c|c|c|c|c|}
\hline & Ölçek Alt Boyutları & Madde Sayısı & $\mathbf{n}$ & Ort. & Ss. & Çar. & Bas. & $\alpha$ \\
\hline \multirow{6}{*}{ BZEÖ } & Birey Psikolojisi & 3 & 216 & 2.41 & 0.73 & -0.11 & -0.44 & 0.62 \\
\hline & Bilgi Eksikliği & 3 & 216 & 2.60 & 0.91 & -0.25 & -.0 .93 & 0.87 \\
\hline & Tesis & 3 & 216 & 3.13 & 1.12 & -0.24 & -0.89 & 0.79 \\
\hline & Arkadaş Eksikliği & 3 & 216 & 2.29 & 0.95 & 0.10 & -1.05 & 0.89 \\
\hline & Zaman & 3 & 216 & 2.56 & 0.75 & -0.37 & -0.25 & 0.66 \\
\hline & İlgi Eksikliği & 3 & 216 & 2.57 & 0.85 & -0.30 & -0.66 & 0.80 \\
\hline \multirow{5}{*}{ SZİÖ } & Çekicilik & 3 & 216 & 3.24 & 1.18 & -0.36 & -0.97 & 0.87 \\
\hline & Önem Verme & 3 & 216 & 3.02 & 1.16 & -0.12 & -0.93 & 0.87 \\
\hline & Sosyal İlişki & 3 & 216 & 3.17 & 1.05 & -0.20 & -0.65 & 0.73 \\
\hline & Özdeşleşme & 3 & 216 & 3.10 & 1.11 & -0.23 & -1.04 & 0.80 \\
\hline & Kendini İfade & 3 & 216 & 2.99 & 1.10 & -0.91 & -0.85 & 0.82 \\
\hline
\end{tabular}

Tablo 1'de katılımcıların ölçek alt boyutlarından aldıkları ortalama puanlar verilmiştir. Analiz sonuçlarına göre; BZEÖ'nin alt boyutlarında en yüksek ortalamanın "Tesis" (3.13), en düşük ortalamanın ise, "Arkadaş Eksikliği” (2.29) alt boyutunda olduğu tespit edilmiştir. SZīÖ'nin alt boyutları incelendiğinde ise, en yüksek "Çekicilik" (3.24) alt boyutunda, en düşük ise "Kendini İfade" (2.99) alt boyutunda olduğu saptanmıştır. BZEÖ’nin iç tutarlılık katsayısı 0.62-0.89 ve SZiÖ için ise 0.73-0.87 arasında değişmektedir. 
Tablo 2. Katılımcıların cinsiyetlerine göre manova sonuçları (BZEÖ-SZIÖ)

\begin{tabular}{lcccc}
\hline \multirow{2}{*}{ Ölçekler } & \multicolumn{2}{c}{ Kadin (n=128) } & \multicolumn{2}{c}{ Erkek $(\boldsymbol{n}=\mathbf{8 8})$} \\
& Ort. & Ss. & Ort. & Ss. \\
\hline BZEÖ & & & & \\
$\quad$ Birey Psikolojisi & 2.39 & 0.69 & 2.44 & 0.80 \\
Bilgi Eksikliği & 2.64 & 0.92 & 2.53 & 0.89 \\
Tesis & 3.04 & 1.10 & 3.28 & 1.15 \\
Arkadaş Eksikliği & 2.26 & 0.96 & 2.32 & 0.93 \\
Zaman & 2.59 & 0.73 & 2.51 & 0.78 \\
İlgi Eksikliği & 2.60 & 0.83 & 2.52 & 0.90 \\
\hline SZi̇ö & & & & \\
$\quad$ Çekicilik & 3.16 & 1.14 & 3.35 & 1.22 \\
Önem Verme & 2.85 & 1.09 & 3.28 & 1.21 \\
Sosyal İlişki & 3.10 & 1.02 & 3.27 & 1.08 \\
Özdeşleşme & 3.00 & 1.09 & 3.24 & 1.13 \\
$\quad$ Kendini İfade & 2.87 & 1.04 & 3.16 & 1.17 \\
\hline
\end{tabular}

Tablo 2'de MANOVA analizi sonuçlarına göre; cinsiyetin BZEÖ'nin puanları üzerindeki ana etkisinin anlamlı olmadığ 1 belirlenmiştir $\left[\lambda=0.973, \mathrm{~F}_{(6,209)}=.984 ; \mathrm{p}>0.05\right]$. Bununla birlikte bireylerin "BZEÖ" nin alt boyut puanlarının anlamlı farklılık göstermediği saptanmıştır. Yine, cinsiyet değişkenin SZİÖ’nin puanları üzerindeki ana etkisinin anlamlı olmadığı belirlenmiştir. $\left[\lambda=0.952, \mathrm{~F}_{(5,210)}=2.125 ; \mathrm{p}>0.05\right]$. Fakat, "Önem Verme" alt boyutunda anlamlı farkl111k olduğu belirlenmiştir $\left[\mathrm{F}_{(1-214)}=7.313 ; \mathrm{p}<0.05\right]$. Ortalama puanlar incelendiğinde ise, erkeklerin önem verme ortalama puanları kadınlara oranla daha yüksek olduğu tespit edilmiştir.

Tablo 3. Katılımcıların haftalık fitness merkezini kullanım sıklıklarına göre manova sonuçları (BZEÖSZIÖ)

\begin{tabular}{|c|c|c|c|c|c|c|}
\hline \multirow{2}{*}{ Ölçekler } & \multicolumn{2}{|c|}{ 1-3 Gün $(n=86)$} & \multicolumn{2}{|c|}{ 4-6 Gün $(n=47)$} & \multicolumn{2}{|c|}{7 Gün ve Üzeri $(n=83)$} \\
\hline & Ort. & Ss. & Ort. & Ss. & Ort. & Ss. \\
\hline \multicolumn{7}{|l|}{ BZEÖ } \\
\hline Birey Psikolojisi & 2.24 & 0.70 & 2.55 & 0.67 & 2.52 & 0.77 \\
\hline Bilgi Eksikliği & 2.65 & 0.96 & 2.63 & 0.79 & 2.51 & 0.91 \\
\hline Tesis & 2.76 & 1.23 & 3.52 & 0.92 & 3.30 & 1.00 \\
\hline Arkadaş Eksikliği & 2.37 & 0.94 & 2.35 & 0.94 & 2.15 & 0.89 \\
\hline Zaman & 2.60 & 0.81 & 2.54 & 0.71 & 2.52 & 0.72 \\
\hline İlgi Eksikliği & 2.69 & 0.86 & 2.62 & 0.78 & 2.41 & 0.87 \\
\hline \multicolumn{7}{|l|}{ SZİÖ } \\
\hline Çekicilik & 2.84 & 1.28 & 3.60 & 1.05 & 3.44 & 1.02 \\
\hline Önem Verme & 2.60 & 1.20 & 3.31 & 1.04 & 3.30 & 1.05 \\
\hline Sosyal İlișki & 2.95 & 1.12 & 3.40 & 1.00 & 3.26 & 0.96 \\
\hline Özdeșleșme & 2.72 & 1.20 & 3.51 & 0.94 & 3.25 & 0.99 \\
\hline Kendini İfade & 2.66 & 1.21 & 3.36 & 0.97 & 3.12 & 0.97 \\
\hline
\end{tabular}

Tablo 3'te MANOVA analizi sonuçlarına göre, bireylerin haftalık fitness merkezini kullanım sıklıklarının BZEÖ'nin puanları üzerindeki ana etkisinin anlamlı olduğu ortaya çıkmıştır $[\lambda=$ $\left.0.825, \mathrm{~F}_{(12,416)}=3.495 ; \mathrm{p}>0.05\right]$. Alt boyutlar düzeyinde ise, "Birey Psikolojisi" $\left[\mathrm{F}_{(2-213)}=4.236\right.$; $\mathrm{p}<0.05]$ ile "Tesis" $\left[\mathrm{F}_{(2-213)}=8.936 ; \mathrm{p}<0.05\right]$ alt boyutlarında anlamlı farklılık olduğu belirlenmiştir. Fitness merkezine haftalık 4-6 gün arasında kullanan bireylerin ortalama puanları diğer bireylerin puanlarından daha yüksek olduğu saptanmıştır. Katılımcıların haftalık fitness merkezini kullanım sıklıklarının SZİÖ’nin alt boyutları üzerindeki ana etkisinin anlamlı olduğu belirlenmiştir $\left[\lambda=0.875, \mathrm{~F}_{(10,418)}=2.877 ; \mathrm{p}<0.05\right]$. Alt boyutlar düzeyinde ise, "Çekicilik" $\left[\mathrm{F}_{(2-213)}=9.021 ; \mathrm{p}<0.05\right]$, "Önem Verme" $\left[\mathrm{F}_{(2-213)}=10.529 ; \mathrm{p}<0.05\right]$, "Sosyal İlişki" $\left[F_{(2-213)}=3.314 ; p<0.05\right]$, "Özdeşleşme" $\left[F_{(2-213)}=9.436 ; p<0.05\right]$ ve "Kendini İfade" $\left[F_{(2-}\right.$ 213) $=7.446 ; \mathrm{p}<0.05$ ] alt boyutlarında anlamlı farklılık saptanmıştır. Bu farklılık ortalama puanlar dikkate alındığında haftalık fitness merkezini 4-6 gün kullananlardan kaynaklandığı ortaya çıkmıştır. 

araştırma. Spor Bilimleri Araştırmaları Dergisi, 6(1), 49-61.

Tablo 4. Refah durumuna göre katılımcıların manova sonuçları (BZEÖ-SZIÖ)

\begin{tabular}{|c|c|c|c|c|c|c|}
\hline \multirow{2}{*}{ Ölçekler } & \multicolumn{2}{|c|}{ Kötüi $(n=39)$} & \multicolumn{2}{|c|}{ Normal $(n=98)$} & \multicolumn{2}{|c|}{$\dot{I} y i(n=79)$} \\
\hline & Ort. & Ss. & Ort. & Ss. & Ort. & Ss. \\
\hline \multicolumn{7}{|l|}{ BZEÖ } \\
\hline Birey Psikolojisi & 2.54 & 0.75 & 2.44 & 0.71 & 2.31 & 0.75 \\
\hline Bilgi Eksikliği & 2.85 & 0.86 & 2.56 & 0.85 & 2.52 & 0.98 \\
\hline Tesis & 3.08 & 1.26 & 3.10 & 1.07 & 3.20 & 1.12 \\
\hline Arkadaş Eksikliği & 2.31 & 0.80 & 2.20 & 0.93 & 2.39 & 1.03 \\
\hline Zaman & 2.50 & 0.68 & 2.60 & 0.74 & 2.53 & 0.80 \\
\hline İlgi Eksikliği & 2.83 & 0.72 & 2.52 & 0.85 & 2.50 & 0.90 \\
\hline \multicolumn{7}{|l|}{ SZİÖ } \\
\hline Çekicilik & 3.05 & 1.31 & 3.25 & 1.13 & 3.31 & 1.18 \\
\hline Önem Verme & 2.87 & 1.25 & 3.03 & 1.08 & 3.10 & 1.22 \\
\hline Sosyal İlişki & 3.05 & 1.25 & 3.10 & 0.95 & 3.31 & 1.05 \\
\hline Özdeşleşme & 3.00 & 1.31 & 3.10 & 1.07 & 3.15 & 1.07 \\
\hline Kendini İfade & 2.90 & 1.30 & 2.94 & 0.97 & 3.10 & 1.16 \\
\hline
\end{tabular}

Tablo 4'te MANOVA analizi sonuçlarına göre; katılımcıların refah durumlarının BZEÖ'nin puanları üzerindeki temel etkinin anlamlı bulunmadığı belirlenmiştir $\left[\lambda=0.919, \mathrm{~F}_{(12,416)}=1.497\right.$; p>0.05]. Bireylerin "BZEÖ" nin alt boyut puanları arasında anlamlı farklılık göstermediği belirlenmiştir. Benzer şekilde, refah durumunun SZIÖ'nin puanları üzerindeki ana etkisinin anlamlı olmadığını göstermektedir $\left[\lambda=0.977, \mathrm{~F}_{(10,418)}=.482 ; \mathrm{p}>0.05\right]$. Katılımcıların "SZİÖ" nin alt boyut puanları arasında anlamlı farklılık göstermediği belirlenmiştir.

Tablo 5. Katılımcıların haftalık serbest zaman sürelerine göre manova sonuçları (BZEÖ-SZIÖ)

\begin{tabular}{|c|c|c|c|c|c|c|c|c|}
\hline \multirow{2}{*}{ Ölçekler } & \multicolumn{2}{|c|}{ 1-5 Saat $(n=35)$} & \multicolumn{2}{|c|}{ 6-10 Saat $(n=82)$} & \multicolumn{2}{|c|}{ 11-15 Saat $(n=44)$} & \multicolumn{2}{|c|}{16 Saat ve $\ddot{U} z$ eri $(n=55)$} \\
\hline & Ort. & Ss. & Ort. & Ss. & Ort. & Ss. & Ort. & Ss. \\
\hline \multicolumn{9}{|l|}{$\overline{\text { BZEÖ }}$} \\
\hline Birey Psikolojisi & 2.39 & 0.78 & 2.45 & 0.71 & 2.36 & 0.86 & 2.43 & 0.64 \\
\hline Bilgi Eksikliği & 2.69 & 1.00 & 2.77 & 0.88 & 2.39 & 0.99 & 2.45 & 0.77 \\
\hline Tesis & 3.35 & 1.21 & 3.11 & 1.13 & 3.09 & 1.17 & 3.07 & 1.02 \\
\hline Arkadaş Eksikliği & 2.33 & 0.86 & 2.34 & 0.94 & 2.29 & 0.93 & 2.19 & 1.03 \\
\hline Zaman & 2.60 & 0.79 & 2.53 & 0.77 & 2.42 & 0.81 & 2.68 & 0.63 \\
\hline İlgi Eksikliği & 2.72 & 0.87 & 2.62 & 0.86 & 2.50 & 0.93 & 2.44 & 0.78 \\
\hline \multicolumn{9}{|l|}{ SZİÖ } \\
\hline Çekicilik & 3.28 & 1.12 & 3.22 & 1.19 & 3.19 & 1.28 & 3.26 & 1.14 \\
\hline Önem Verme & 2.92 & 1.05 & 3.01 & 1.23 & 3.03 & 1.24 & 3.10 & 1.08 \\
\hline Sosyal İlişki & 3.01 & 1.01 & 3.34 & 1.06 & 3.06 & 1.16 & 3.10 & 0.93 \\
\hline Özdeşleşme & 3.28 & 1.24 & 3.08 & 1.17 & 2.96 & 1.12 & 3.11 & 0.93 \\
\hline Kendini İfade & 2.93 & 1.15 & 3.08 & 1.13 & 2.95 & 1.22 & 2.93 & 0.95 \\
\hline
\end{tabular}

Tablo 5'te MANOVA analizi sonuçlarına göre; katılımcıların haftalık serbest zaman sürelerinin BZEÖ’nin puanları üzerindeki ana etkisinin anlamlı olmadığı belirlenmiştir $[\lambda=$ 0.902, $\left.\mathrm{F}_{(18,585)}=1.207 ; \mathrm{p}>0.05\right]$. Katılımciların "BZEÖ" nin alt boyut puanlarının anlaml farklılık göstermediği belirlenmiştir. Benzer şekilde, katılımcıların haftalık serbest zaman sürelerinin SZİÖ'nin puanları üzerindeki ana etkisinin anlamlı olmadığ gibi alt boyut puanlarından da anlamlı farklılık olmadığı belirlenmiştir $\left[\lambda=0.910, \mathrm{~F}_{(15,574)}=1.333 ; \mathrm{p}>0.05\right]$. 
Tablo 6. Yaş ile BZEÖ-SZIÖ puanları arasındaki korelasyon sonuçları

\begin{tabular}{|c|c|c|c|c|c|c|c|c|c|c|c|c|}
\hline & Yaş & F1 & $\mathrm{F} 2$ & F3 & F4 & F5 & F6 & F7 & F8 & F9 & F10 & F11 \\
\hline Yaş & 1 & & & & & & & & & & & \\
\hline F1 & .092 & 1 & & & & & & & & & & \\
\hline F2 & .058 & $.442^{2 *}$ & 1 & & & & & & & & & \\
\hline F3 & $.213^{* *}$ & $.116^{* *}$ & $.149^{* * *}$ & 1 & & & & & & & & \\
\hline F4 & -.057 & $.266^{* *}$ & $.288^{* *}$ & $.146^{* *}$ & 1 & & & & & & & \\
\hline F5 & .069 & $.383^{* * *}$ & $.425^{* *}$ & $.050^{* *}$ & $.518^{* *}$ & 1 & & & & & & \\
\hline F6 & -.004 & $.416^{* *}$ & $.438^{* * *}$ & $.107^{* *}$ & $.489^{* * *}$ & $.560^{* *}$ & 1 & & & & & \\
\hline F7 & $.198^{* * *}$ & -.003 & -.006 & -.870 & -.117 & -.006 & -.092 & 1 & & & & \\
\hline F8 & $.195^{* *}$ & -.083 & -.011 & -.724 & -.080 & -.009 & -.059 & $.774^{* * *}$ & 1 & & & \\
\hline F9 & .108 & -.003 & -.022 & -.712 & -.062 & -.037 & -.030 & $.762^{* *}$ & $.657^{* * *}$ & 1 & & \\
\hline F10 & $.209^{* *}$ & -.015 & -.005 & -.911 & -.136 & -.024 & -.071 & $.841^{* *}$ & $.784^{* *}$ & $.686^{* *}$ & 1 & \\
\hline F11. & $.204^{* *}$ & -.010 & -.071 & -.854 & -.025 & -.036 & -.093 & $.777^{* *}$ & $.682^{* * *}$ & $.762^{* *}$ & $.780^{* *}$ & 1 \\
\hline
\end{tabular}

Tablo 6'da Pearson korelasyon analizi sonuçlarına göre; Yaş ile BZEÖ'nin alt boyutları arasında sadece "Tesis" alt boyutu ile düşük düzeyde ve pozitif ilişkili olduğu ortaya çıkmıştır. Yaş ile SZIÖ’nin alt boyutları arasında ise "Çekicilik", "Önem Verme", "Özdeşleşme" ve "Kendini İfade" alt boyutları arasında pozitif ve düşük düzeyde anlamlı bir ilişkinin olduğu belirlenmiştir $(p<0.01)$. Son olarak ise, "BZEÖ’nin alt boyutları" ile "SZIOÖ'nin alt boyutları" arasında anlamlı bir ilişki olmadığı belirlenmiştir.

\section{TARTIŞMA VE SONUÇ}

Çalışma sonuçlarına göre, bireylerin serbest zaman aktivitelerine katılımını engelleyen en önemli faktörün "Tesis" olduğu belirlenmiştir. Elde edilen bu bulgular 1şığında, alanyazın incelendiğinde; Demirel ve Harmandar (2009) ve Koçak (2017) tarafindan yapılan çalışmalarda katılımcıların serbest zaman aktivitelerine katılımlarını engelleyen en önemli faktörün tesis olduğu belirtilmiştir. Gürbüz ve Henderson (2014) tarafından Türk halkının serbest zaman tercihleri ve engel düzeylerini belirlemeye yönelik yaptıkları çalışmada, tesis/ulaşım/hizmet gibi yapısal engellerin serbest zaman engelleri arasında en büyük faktör olduğu belirtilmiştir. Serbest zaman ilgilenimini etkileyen en önemli faktör ise, "Çekicilik" olarak belirlenmiştir. Bu sonuç Seviç (2019) tarafından Sakarya üniversitesi öğrencilerinin serbest zaman engelleri ile ilgilenim düzeylerini belirlemeye yönelik yapılan çalışmanın sonuçları ile paralellik göstermektedir. Yine, alanyazında Kyle vd., (2006), Havitz vd., (2013) ve Aydın ve Yaşartürk (2016) tarafından yapılan çalışmaların sonucu ile bu çalışmanın sonuçları paralellik göstermektedir. Cinsiyet değişkeni açısından katılımcıların serbest zaman engel düzeyleri incelediğinde alt boyutlar üzerindeki temel etkinin anlamlı olmadığ 1 ve alt boyutlar düzeyinde de farklılık görülememiştir. Alanyazında yapılan çalışmalar incelendiğinde; Koçak (2017) ve Sarol (2017) tarafından yapılan çalışmaların sonuçları ile bu çalışmanın sonuçları paralellik gösterirken, Ayhan vd., (2018), Çakır vd., (2016), Demirel vd., (2017) ve Soyer vd., (2017) tarafından yapılan çalışmaların sonuçlarıyla paralellik göstermemektedir. Katılımcıların serbest zaman ilgilenim ortalama puanları cinsiyet değişkenine göre incelendiğinde, "Önem Verme" alt boyutunda erkeklerin puanları kadınların puanlarına oranla daha yüksek olduğu saptanmıştır. Bu durum erkek bireylerin katılım gösterdikleri serbest zaman aktivitelerinin onların hayatlarının merkezinde yer aldığı şeklinde açıklanabilir. Ayrıca, ulaşılan bu sonuçlar literatürde Demirel (2019) ve Seviç (2019) tarafından yapılan çalışmaların sonuçları ile paralellik gösterirken, Aydın (2016) tarafından yapılan çalışmanın sonuçları ile örtüşmemektedir. Katılımcıların haftalık fitness merkezini 
kullanım sıklıklarına göre serbest zaman ilgilenim düzeyleri incelendiğinde alt boyutlar üzerinde temel etkinin anlamlı olduğu ve tüm alt boyutlarda anlamlı farklılık olduğu saptanmıştır. Fitness merkezine haftalık 4-6 gün arasında giden bireylerin ilgilenim düzeylerin daha fazla olduğu sonucuna ulaşılmışır. Bu bulgular ışı̆̆ında elde edilen sonuçlar Aydın (2016) tarafindan fitness katılımcılarının serbest zaman aktivitelerine yönelik ilgilenim ve mutluluk düzeylerine yönelik yaptığı çalışmanın sonuçları ile paralellik göstermektedir. Benzer şekilde, Seviç (2019) tarafindan üniversite öğrencilerinin serbest zaman engelleri ile ilgilenimleri arasındaki ilişkiyi inceleyen çalışmada bireylerin ilgilenim düzeylerinde serbest zaman katılım sıklıklarına göre farkllılk olduğu belirlenmiştir. Bireylerin haftalık fitness merkezini kullanım sıklıklarına göre engel düzeyleri incelendiğinde; fitness merkezine haftalık 4-6 gün arasında giden bireylerin "Birey Psikolojisi" ve "Tesis" alt boyut puanlarının daha yüksek olduğu belirlenmiştir. Diğer bir ifadeyle, haftada 4-6 gün arasında fitness merkezine giden bireylerin en çok birey psikolojisi ve tesis yönünden engellerle karşılaştıkları belirlenmiş̧tir. Elde edilen bulgular ışığında, alanyazında yapılan araştırmalar incelendiğinde; Ayçicek (2019) tarafindan yapılan araştırmada bireylerin rekreatif aktivitelere katılım sıklıklarına göre engel düzeyleri incelendiğinde rekreatif aktivitelere nadir katılan bireylerin birey psikolojisi engel düzeyleri diğer bireylere oranla daha fazla engellerle karşılaştıkları belirlenmiş̧tir. Ayçicek (2019) tarafindan yapılan araştırmanın sonuçları ile bu araştırmanın sonuçları örtüşmektedir.

Çalışma sonuçlarına göre refah durumu değişkeninin engel düzeyleri üzerinde anlamlı farklılık yaratan bir değişken olmadığı sonucuna varılmıştır. Alanyazında yer alan çalışmalar değerlendirildiğinde ise; Soyer vd., (2017), tarafından yapılan çalışmanın sonuçları ile örtüşürken, Tolukan (2010) tarafindan yapılan çalışmaların sonuçlarıyla örtüşmemektedir. Katılımcıların serbest zaman ilgilenim düzeylerinin refah durumlarına göre ana etkisinin anlamlı olmadığı gibi alt boyutlarda da farklılık tespit edilememiş̧tir. Diğger bir ifadeyle, refah durumu iyi olan bireylerin ilgilenim düzeyleri diğer bireylerden daha fazla olmasına rağmen bu fark anlamlı değildir. Haftalık serbest zaman sürelerine göre serbest zaman ilgilenim düzeyleri incelendiğinde ise anlamlı farklılık ortaya çıkmadığı belirlenmiştir. Ekinci ve Yalçın (2019) tarafindan yapılan çalı̧̧ada katılımcıların günlük serbest zaman sürelerine göre ilgilenim düzeyleri arasında farklılık bulunmuştur. Bu noktadan hareketle, Ekinci ve Yalçın (2019) tarafından yapılan çalışmanın sonuçları ile bu çalışmanın sonuçları örtüşmemektedir. Katılımcıların haftalık serbest zaman sürelerinin serbest zaman engel düzeyleri üzerindeki ana etkinin anlamlı olmadığı gibi alt boyutlar arasında da anlamlı farklılık olmadığı belirlenmiştir. $\mathrm{Bu}$ bulgular 1şığında, Akyüz (2016) tarafindan yapılan araştırmanın sonuçlarıyla, bu araştırmanın sonuçları örtüşmemektedir. Katılımcıların yaşları ile serbest zaman engel düzeyleri arasında sadece "Tesis" alt boyutunda pozitif yönde ve düşük düzeyde bir ilişki olduğu belirlenmiştir. Elde edilen bulgular ışı̆̆ında alanyazında yapılan çalışmalar incelendiğinde ise, Ayçicek (2019) ile Kesici (2019) tarafindan yapılan çalışmada serbest zaman engelleri ile yaş arasında ilişki olmadığı belirlenmiştir. Yaş ile serbest zaman ilgilenim arasındaki ilişkiyi incelendiğinde ise, Yaş ile SZIÖ'nün alt boyutlarından "Çekicilik", "Önem Verme", "Özdeşleşme" ve "Kendini İfade" arasında ise düşük düzeyde fakat pozitif bir ilişki olduğu belirlenmiş̧tir. Konuya ilişkin alanyazında yapılan araştırmalar incelendiğinde ise; Demirel (2019) tarafindan yapılan çalışmada bireylerin yaşları ile serbest zaman ilgilenim düzeyleri arasında ilişki bulunamamıştır. Bu bağlamda, Demirel (2019) tarafindan yapılan çalışmanın sonuçları ile bu çalışmanın sonuçları örtüşmemektedir. Son olarak ise, BZEÖ ile 
SZİÖ arasında istatistiksel olarak anlamlı bir ilişki olmadığı belirlenmiştir. Konuya ilişkin alanyazında yapılan araştırmalar incelendiğinde Seviç (2019) tarafından yapılan çalışmada BZEÖ’nin "Birey Psikolojisi”, "Bilgi Eksikliği”, “Tesis” ve “Zaman” ile SZİÖ’nin "Sosyal İlişki”" ve "Özdeşleşme" alt boyutları arasında anlamlı bir ilişki olmadığı saptanmıştır. Bu bağlamda Seviç (2019) tarafından yapılan araştırmanın sonuçları ile bu çalışmanın sonuçları örtüşmektedir.

\section{SONUC}

Katılımcıların cinsiyetlerine göre engel düzeylerinin farklılık göstermediği, erkeklerin ise serbest zamanda katılım gösterdikleri aktivitelere kadınlara oranla daha fazla önem verdikleri anlaşılmaktadır. Bireylerin refah durumlarına göre engel ve ilgilenim düzeyleri farklılaşmamaktadır. Haftalık fitness merkezine 4-6 gün arasında giden katılımcıların ilgilenim düzeylerinin daha yüksek olduğu saptanmıştır. Bireylerin haftalık serbest zaman sürelerine göre engel ve ilgilenim düzeylerinin farklılık göstermediği belirlenmiştir. Bireylerin yaşları arttıkça tesis yönünden engellerle karşılaştıkları ve ilgilenim düzeylerininde arttığ gözlenmiştir. Son olarak ise, bireylerin serbest zaman engel düzeyleri ile ilgilenim düzeyleri arasında ilişki olmadığı sonucuna ulaşılmıştır. Sonuç olarak, bireylerin gündelik yaşamlarında karşılaştıkları olumsuz durumların etkisini azaltmak amacıyla serbest zaman aktivitelerine katılım gösterdikleri bilinmektedir. Bu bağlamda, bireylerin serbest zaman aktivitelerine katılımlarını engelleyen faktörler ile serbest zaman aktivitelerine yönelik ilgilenim düzeylerinin belirlenmesi bireylerin yaşamlarına olumlu katkı sağlayacağı düşünülmektedir.

Çıkar Çatışması: Çalışma kapsamında herhangi bir kişisel ve finansal çıkar çatışması bulunmamaktadır.

Araştırmacıların Katkı Oranı Beyanı: Araştırma dizaynı, İstatistik analiz, Makalenin hazırlanması, Verilerin toplanması; yazar tarafından gerçekleştirilmiştir.

\section{Etik Kurul İzni ile İlgili Bilgiler}

Kurul Adı: İstanbul Üniversitesi-Cerrahpaşa Sosyal ve Beşeri Bilimler Araştırmaları Etik Kurulu Başkanlığ

Tarih: 02.06.2020

Sayı/Karar No: 71884/109 
Serdar, E. (2021). Serbest zaman engelleri ile ilgilenim arasındaki ilişki: Fitness merkezi katılımcıları üzerine bir araştırma. Spor Bilimleri Araştırmaları Dergisi, 6(1), 49-61.

\section{KAYNAKLAR}

Akyüz, F. (2016). Halkın boş zaman etkinliklerine katılımlarına engel olan faktörlerin belirlenmesi: (Erzurum ili örneği). Sosyal Bilimler Enstitüsü. Yüksek Lisans Tezi. Ağrı İbrahim Çeçen Üniversitesi: Ağrı.

Alexandris, K. \& Carroll, B. (1997). An analysis of leisure constraints based on different recreational sport participation levels: results from a study in greece. Leisure Sciences, 19(1), 1-15. https://doi.org/10.1080/01490409709512236

Alexandris, K., Du, J., Funk, D. \& Theodorakis, N.D. (2017). Leisure constraints and the psychological continuum model: a study among recreational mountain skiers. Leisure Studies, 36(5), 670-683. DOI: $10.1080 / 02614367.2016 .1263871$

Alexandris, K., Kouthouris, C., Funk, D. \& Chatzigianni, E. (2008). Examining the relationships between leisure constraints, involvement and attitudinal loyalty among greek recreational skiers. European Sport Management Quarterly, 8(3), 247-264. https://doi.org/10.1080/16184740802224175

Alexandris, K., Kouthouris, C., Funk, D. \& Tziouma, O. (2013). The use of negotiation strategies among recreational participants with different involvement levels: the case of recreational swimmers. Leisure Studies, 32(3), 299-317. https://doi.org/10.1080/02614367.2012.660189

Alexandris, K., Tsorbatzoudis, C. \& Grouios, G. (2002). Perceived constraints on recreational sport participation: investigating their relationship with intrinsic motivation, extrinsic motivation and amotivation. Journal of Leisure Research, 34(3), 233-252. https://doi.org/10.1080/00222216.2002.11949970

Ayçicek, C.N. (2019). Beden eğitimi öğretmeni adaylarının serbest zaman aktivitelerine katılımını kolaylaştıran ve engelleyen faktörlerin belirlenmesi. Lisansüstü Eğitim Enstitüsü. Yüksek Lisans Tezi, Trabzon Üniversitesi: Trabzon.

Aydın, İ. (2016) Fitness katılımcılarının rekreasyonel etkinliklere yönelik ilgilenim ve mutluluk düzeylerinin belirlenmesi. Sağlık Bilimleri Enstitüsü. Yüksek Lisans Tezi, Gazi Üniversitesi: Ankara.

Aydın, İ. \& Yaşartürk, F. (2016). Rekreasyonel etkinliklere yönelik fitnes katılımcılarının ilgilenim düzeyleri: Demografik özelliklere göre durumu. International Journal of Science Culture and Sport, 4 (Special İssue 3), 704-711. [Erişim adresi: https://dergipark.org.tr/tr/download/article-file/285512]

Ayhan, C., Ekinci, N.E., Yalçın, İ. \& Yiğit, Ş. (2018). Investigation of constraints that occur during participation in leisure activities by high school students: a sample of Turkey. Education Sciences, 8(2), 1-9.

Bright, A.D. (2000). The role of social marketing in leisure and recreation management. Journal of Leisure Research, 32(1), 12-17. https://doi.org/10.1080/00222216.2000.11949878

Çakır, V.O., Şahin, S., Serdar, E. \& Parlakkılıç, Ş. (2016). Kamu çalışanlarının serbest zaman engelleri ile yaşam tatmini düzeylerinin incelenmesi. Journal of Tourism Theory and Research, 2(2), 135-141. https://doi.org/10.24288/jttr.279185

Chang, H.H. (2017). Gender differences in leisure involvement and flow experience in professional extreme sport activities, World Leisure Journal, 59(2), 124-139. https://doi.org/10.1080/16078055.2016.1166152

Chang, S. \& Gibson, H.J. (2011). Physically active leisure and tourism connection: leisure involvement and choice of tourism activities among paddlers. Leisure Sciences, 33(2), 162-181. https://doi.org/10.1080/01490400.2011.550233

Chen, Z.Y. (2001). The study of elementary teachers' leisure participation, experience in leisure benefits, and work satisfaction in Taipei County. National Taiwan Normal University.

Cheng, T.M. \& Tsaur, S.H. (2012). The relationship between serious leisure characteristics and recreation involvement: a case study of Taiwan's surfing activities. Leisure Studies, 31(1), 53-68. https://doi.org/10.1080/02614367.2011.568066

Crawford, D.W. \& Godbey, G. (1987). Reconceptualizing barriers to family leisure. Leisure Sciences, 9(2), 119127. https://doi.org/10.1080/01490408709512151 
Serdar, E. (2021). Serbest zaman engelleri ile ilgilenim arasındaki ilişki: Fitness merkezi katılımcıları üzerine bir araştırma. Spor Bilimleri Araştırmaları Dergisi, 6(1), 49-61.

Demirel, M. (2019). Leisure involvement and happiness levels of individuals having fitness center membership. Journal of Education and Learning, 8(6), 140-149. https://doi.org/10.5539/jel.v8n6p140

Demirel, M. \& Harmandar, D. (2009). Üniversite öğlencilerinin rekreasyonel etkinliklere katılımlarında engel oluşturabilecek faktörlerin belirlenmesi. International Journal of Human Sciences, 6(1), 838-846.

Demirel, M., Demirel, D.H. \& Serdar, E. (2017). Constraints and perceived freedom levels in the leisure of university students. Journal of Human Sciences, 14(1), 789- 795. https://doi.org/10.14687/jhs.v13i3.nnnn

Eccles, J.S. (2005). Studying the development of learning and task motivation. Learning and Instruction, 15(2), $161-171$.

Ekinci, N.E. \& Yalçın, H. (2019). Leisure involvement level of 40 and over aged individuals. Journal of Educational Issues. 5(2), 170-181. https://doi.org/10.5296/jei.v5i2.15683

Eskiler, E., Y1ldız, Y. \& Ayhan, C. (2019). The effect of leisure benefits on leisure satisfaction: extreme sports. Turkish Journal of Sport and Exercise, 21(1):16-20. https://doi.org/10.15314/tsed.522984

Gürbüz, B. \& Henderson, H.A. (2014). Leisure activity preferences and constraints: perspectives from Turkey, World Leisure Journal. 56(4), 300-316. https://doi.org/10.1080/16078055.2014.958195

Gürbüz, B., Çimen, Z. \& Aydın, İ. (2018). Serbest zaman ilgilenim ölçeği: Türkçe formu geçerlik ve güvenirlik çalışması. Sportmetre Beden Eğitimi ve Spor Bilimleri Dergisi, 16(4), 256-265. DOI: 10.1501/Sporm_0000000408

Gürbüz, B., Öncü, E. \& Emir, E. (2020). Boş zaman engelleri ölçeği: kısa formunun yap1 geçerliğinin test edilmesi. Spor ve Performans Araştırmalarl Dergisi, 11(2), 120-131. https://doi.org/10.17155/omuspd.602660

Gürbüz, B. \& Karaküçük, S. (2007). Boş zaman engelleri ölçeği-28: Ölçek geliştirme, geçerlik ve güvenirlik çalışması. Gazi Beden Eğitimi ve Spor Bilimleri Dergisi, 12(1), 3-10

Havitz, M.E. \& Dimanche, F. (1997). Leisure involvement revisited: conceptual conundrums and measurement advances. Journal of Leisure Research, 29(3), 245- 278. https://doi.org/10.1080/00222216.1997.11949796

Havitz, M.E., Kacznski, A.T. \& Mannell, R.C. (2013). Exploring relationships between physical activity, leisure involvement, self-efficacy and motivation via participant segmentation. Leisure Sciences, 35(1), 45-62. https://doi.org/10.1080/01490400.2013.739890

Ho, T.K. (2008). A study of leisure attitudes and benefits for senior high school students at Ping-Tung city and country in Taiwan. unpublished doctoral dissertation. United States Sports Academy, Daphne, AL.

Hung, H.J. (2012). A study on leisure benefits breaking through leisure activities. Journal of National Taiwan Normal University, 3(4), 77-92.

Iso-Ahola, S. E. (1997). A Psychological analysis of leisure and health. In J. Haworth (Ed.), Work, leisure and well-being. New York: Routledge.

Iwasaki, Y. \& Havitz, M.E. (2004). Examining relationships between leisure involvement, psychological commitment and loyalty to a recreation agency. Journal of Leisure Research, 36(1), 45-72. https://doi.org/10.1080/00222216.2004.11950010

Jun, J. \& Kyle, G.T. (2011). The effect of identity conflict/facilitation on the experience of constraints to leisure and constraint negotiation. Journal of Leisure Research, 43(2), 176- 204. https://doi.org/10.1080/00222216.2011.11950232

Karasar, N. (2014). Bilimsel Araştırma Yöntemi. 27 Basım. Nobel yayıncılık: Ankara.

Kesici, M. (2019). Relationship between leisure attitudes and participation obstacles in leisure activities of food and beverage managers. GSI Journals Serie A: Advancements in Tourism, Recreation and Sports Sciences (ATRSS), 2(1), 76-94. https://doi.org/10.5281/zenodo.3360335 
Serdar, E. (2021). Serbest zaman engelleri ile ilgilenim arasındaki ilişki: Fitness merkezi katılımcıları üzerine bir araştırma. Spor Bilimleri Araştırmaları Dergisi, 6(1), 49-61.

Kim, J., Heo, J., Dvorak, R., Ryu, J. \& Han, A. (2018). Benefits of leisure activities for health and life satisfaction among western migrants. Annals of Leisure Research, 21(1), 47-57. https://doi.org/10.1080/11745398.2017.1379421

Koçak, F. (2017). Leisure constrains and facilitators: perspectives from Turkey. European Journal of Physical Education and Sport Science, 3(10), 32-47. Doi: 10.5281/zenodo.852540

Kuo, C.T. (2013). A study of the correlation between leisure benefits and behavioral intentions -using bantou arts and cultural village as an example. International Review of Management and Business Research, 2(4), 1065-1074.

Kuykendall, L., Tay, L. \& Ng, V. (2015). Leisure engagement and subjective well-being: a meta-analysis. Psychological Bulletin, 141(2), 364-403. https://doi.org/10.1037/a0038508

Kyle, G. \& Chick, G. (2004). Enduring leisure involvement: the importance of personal relationships. Leisure Studies, 23(3), 243-266. https://doi.org/10.1080/0261436042000251996

Kyle, G., Absher, J. \& Graefe, A. (2003). The moderating role of place attachment on the relationship between attitudes toward fees and spending preferences. Leisure Sciences. 25(1), 33-50. https://doi.org/10.1080/01490400306552

Kyle, G., Bricker, K., Graefe, A. \& Wickham, T. (2004). An examination of recreationist's relationships with activities and setting. Leisure Sciences, 26(2), 123-142. https://doi.org/10.1080/01490400490432019

Kyle, G., Absher, J., Norman, W., Hammit, W. \& Jodice, L. (2007). A modified involvement scale. Leisure Studies. 26(4), 399-427. https://doi.org/10.1080/02614360600896668

Kyle, G., Absher, J.D., Hammitt, W.E. \& Cavin, J. (2006). An examination of the motivation-Involvement relationship. Leisure Sciences. 28(5), 467-485. https://doi.org/10.1080/01490400600851320

Lapa, T.Y. \& Köse, E. (2018). Serbest zaman engelleri ile engellerle baş etme stratejileri arasındaki ilişkinin incelenmesi: keşifsel bir çalışma. CBÜ Beden Eğitimi ve Spor Bilimleri Dergisi, 13(2), 356-375. https://doi.org/10.33459/cbubesbd.440506

Mannell, R. \& Loucks-Atkinson, A. (2005). Why don't people do what's “good' for them? Crossfertilization among the psychologies of non-participation in leisure, health and exercise behaviours. In E. Jackson (Ed.), Constraints to leisure (pp. 221-232). Pennsylvania: Venture Publishing.

Mannell, R. \& Iwasaki, Y. (2005). Advancing quantitative research on social cognitive theories of the constraintnegotiation process. In E. Jackson (Ed.), Constraints to leisure. Pennsylvania: Venture Publishing: 261278.

Mannell, R.C. \& Stynes D.J. (1991). A retrospective: the benefits of leisure. In B.L. Driver, P.J. Brown \& G.L. Peterson (Eds.), Benefits of leisure. Stage College, PA: Venture Publishing.

Matsumoto, H., Sato, S., Asada, A. \& Chiashi, K. (2018). Exploring the relationship among leisure engagement, affective and cognitive leisure involvement, and subjective happiness: a mediating role of leisure satisfaction. World Leisure Journal, 60(2), 111-126. https://doi.org/10.1080/16078055.2018.1444669

McIntyre, N. \& Pigram, J.J. (1992). Recreation specialization reexamined: The case vehicle-based campers. Leisure Sciences, 14(1), 3-15. https://doi.org/10.1080/01490409209513153

Sarol, H. (2017). Bireylerin fiziksel aktiviteye katılımını engelleyen ve kolaylaştıran faktörlerin belirlenmesi. International Journal of Human Science, 14(4), 4354-4364. Doi:10.14687/jhs.v14i4.5121

Sato, M., Yoshida, M., Wakayoshi, K. \& Shonk, D.J. (2017). Event satisfaction, leisure involvement and life satisfaction at a walking event: the mediating role of life domain satisfaction. Leisure Studies, 36(5), 605-617. https://doi.org/10.1080/02614367.2016.1240221

Serdar, E. \& Ay, S. M. (2016). Üniversite öğrencilerinin serbest zaman etkinliklerine katılım biçimlerine göre tatmin olma ve algılanan özgürlük düzeylerinin incelenmesi. Sosyal Bilimler Dergisi, 3(9), 365-374. https://doi.org/10.16990/SOBIDER.3332 
Serdar, E. (2021). Serbest zaman engelleri ile ilgilenim arasındaki ilişki: Fitness merkezi katılımcıları üzerine bir araştırma. Spor Bilimleri Araştırmaları Dergisi, 6(1), 49-61.

Seviç, M. (2019). Serbest zaman engelleri ve ilgilenimleri arasındaki ilişkinin incelenmesi: Sakarya üniversitesi örneği. Lisansüstü Eğitim Enstitüsü. Yüksek Lisans Tezi, Sakarya Uygulamalı Bilimler Üniversitesi: Sakarya.

Soyer, F., Yıldız, N.O., Harmandar Demirel, D., Serdar, E., Demirel, M., Ayhan, C. \& Demirhan, Ö. (2017). Üniversite öğrencilerinin rekreatif etkinliklere katılımlarına engel teşkil eden faktörler ile katılımcıların yaşam doyumları arasındaki ilişkinin incelenmesi. Journal of Human Sciences, 14(2), 2035-2046. doi:10.14687/jhs.v14i2.4647

Tolukan, E. (2010). Özel yenetekle ilgili bölümlerde okuyan üniversite ögrencilerinin rekreasyonel aktivitelere katılımlarına engel olabilecek unsurların belirlenmesi. Sosyal Bilimler Enstitüsü. Yüksek Lisans Tezi, Niğde Üniversitesi: Niğde.

Wankel, L. M. \& Berger, B. G. (1991). The personal and social benefits of sport and physical activity. in Driver, P.J. Brown \& G.L. Peterson (Eds.), Benefits of leisure stage college. PA: Venture Publishing.

Yan, W. (2013). Correlations of consumers, leisure motivation and leisure value with benefits - a case study on Taiwan international orchid show. International Journal of Academic Research in Business and Social Sciences, 3(3), 267-276.

Bu eser Creative Commons Atıf-GayriTicari 4.0 Uluslararası Lisansı ile lisanslanmıştır. 